\title{
Terrorismo y Guerrilla en la Argentina ${ }^{1}$
}

Héctor Ricardo Leis ${ }^{2}$

Resumo

Tomando como material de análise minhas próprias memórias, o artigo reflete sobre os vínculos analíticos e empíricos entre os fenômenos da revolução, da guerrilha e do terrorismo. A análise das práticas e de concepções de grupos guerrilheiros urbanos da América Latina, em especial dos Montoneros, na Argentina, monstra que o terrorismo estava no centro das estratégias políticas daqueles deste grupo desde o seu início. Ao final, rejeita-se o dualismo entre práticas terroristas advindas da sociedade civil ou do Estado e que penaliza apena este segundo segmento, argumentando-se que ambas foram exercidas contra o conjunto da Comunidade Política. Por esta razão, todos aqueles que colaboraram de uma ou outra maneira se converteram em cúmplices e deveriam ser processados legalmente.

Palavras-Chave: Guerrilha, Terrorismo, Revolução, Montoneros, Argentina.

\section{Terrorism and Guerrilla in Argentina}

\section{Abstract}

Taking as material analysis my own memories, the article reflects on the analytical and empirical linkages between the phenomena of the revolution, guerrilla and terrorism. The analysis of the practices and conceptions of urban guerrilla groups in

\footnotetext{
${ }^{1}$ Este texto es un fragmento del capítulo 1 del libro del autor: Un Testamento de los anos 70: Terrorismo, política y verdad en la Argentina, Buenos Aires: Editora Katz, 2013.

${ }^{2}$ Professor aposentado da Universidade Federal de Santa Catarina.
} 
Latin America, especially the Montoneros in Argentina, demonstrates that terrorism was at the center of the political strategies of this group since its inception. At the end, it rejects the dualism between terrorist practices arising from civil society or from State and penalizes only this second segment, arguing that both were exercised against the entire set of Community Policy. For this reason, all those who collaborated in one way or another have become complicit and should be legally prosecuted.

Keywords: Guerilla, Terrorism, Revolution, Montoneros, Argentina.

El problema ha sido siempre el mismo: los que fueron a la escuela de la revolución aprendieron y supieron de antemano que curso una revolución debe tomar. Fue el curso de los acontecimientos. (...) Ellos habían adquirido la capacidad de representar cualquier papel que el gran drama de la historia les asignara y, si no hubiera otro papel a su disposición que no fuera el de villano, estaban más que dispuestos a aceptarlo, en lugar de quedarse afuera. (...) Hay cierta grandiosidad absurda en el espectáculo de estos hombres - que se atrevieron a desafiar a todos los poderes y las autoridades del mundo, y cuyo coraje no tenía ninguna duda - sometiéndose, a menudo, de la noche a la mañana, con humildad y sin siquiera un grito, a la llamada de la necesidad histórica, por más loco e incongruente que les debe haber parecido el aspecto exterior de esta necesidad. Ellos fueron engañados, no por las palabras de Danton, Robespierre y Saint-Just y todos las otras que les sonaban en los oídos, fueron engañados por la historia y se convirtieron en los locos de la historia. Hannah Arendt (1906-1975). ${ }^{3}$

La mayor diferencia entre los modelos de acción de las guerrillas urbana y rural está en la cuestión del terrorismo. Varios países de América Latina pasaron de un tipo de guerrilla a otro sin darse cuenta del cambio de valores que sigue a este cambio. La idealización romántica de la revolución cubana se extendió

${ }^{3}$ Hannah Arendt. Sobre a Revolução, Lisboa: Relógio D’Água, 2001, p. 68 -69 (traducción al español de H.R.L.). 
a ambos modelos, cuando en realidad la urbana es mucho más terrorismo que guerrilla. Sus miembros pagarían caro ese error.

Los guerrilleros urbanos sólo pensaban en el enemigo, ignoraban el poder deletéreo del terrorismo para la calidad de la guerra. El terror es la mejor palanca para una escalada a los extremos de violencia en los conflictos armados. Carl von Clausewitz, en su conocido libro De la Guerra, comprueba que, en general, las guerras no llegan a los extremos de violencia, aunque conceptualmente las mismas implican dinámicas en que, para ganar, los dos lados son llevados hacia los extremos. ${ }^{4}$ Según el autor, las razones moderadoras del uso de la violencia son muchas, incluyendo la presencia de factores morales, y sobre todo que la guerra siempre se subordina a objetivos políticos. En particular, este último aspecto supone implícitamente que los agentes conservan a lo largo del proceso un grado relativamente alto de racionalidad. Clausewitz no hace referencia a la cuestión del terror, él estudiaba la guerra convencional de su tiempo.Pero aun así es fácil ver que, cuando el terror se introduce en el medio de la guerra, la racionalidad de los actores tiende a eclipsarse y la importancia de los factores morales y políticos a disminuir, ya que aumenta el deseo inmediato de venganza. La cual, paradójicamente, se hace más insaciable cuanto más avanza por el camino del terror.

El terror genera sentimientos profundamente negativos como el miedo y el resentimiento, que alimentan el círculo vicioso de la venganza de las fuerzas combatientes afectadas. Así, el terrorismo lleva la guerra a los extremos del exterminio cruel del enemigo, dejando cada vez más lejos a los factores políticos y morales iniciales. Sólo la rendición incondicional de uno de los lados, y no siempre, puede evitar este exterminio. En algunos casos, como en los Estados totalitarios, incluso después de la eliminación del supuesto enemigo, el terror sigue retroalimentándose a lo largo de los años.

${ }^{4}$ Carl von Clausewitz, Da Guerra, São Paulo: Martins Fontes, 2010. 
En su conocido manual, La Guerra de Guerrillas, publicado en el calor de los combates en Cuba, Che Guevara receta la guerrilla rural para toda América Latina, rechazando explícitamente el terrorismo por considerarlo una acción que dificulta el trabajo político con las masas. ${ }^{5}$ Su opinión reflejaba el consenso del viejo marxismo, que identificaba al terrorismo tradicionalmente con la derecha y repudiaba la atracción que ejercía sobre los anarquistas. ${ }^{6}$ Tras el fracaso de los intentos de guerrilla rural en los años 60, en América Latina se cambia el curso de la dinámica revolucionaria del campo a las ciudades. En este nuevo contexto Carlos Marighella publica, en 1969, el Manual del Guerrillero Urbano, un libro de referencia para los distintos grupos del continente, incluso los argentinos. El líder brasileño caracteriza las ejecuciones, los secuestros y el terrorismo en general como modelos de acción legítimos de la guerrilla urbana, concluyendo con énfasis que "el terrorismo es un arma que el revolucionario no puede abandonar". ${ }^{7}$ Mientras el terror en las zonas rurales era visto como contraproducente, en las ciudades era elogiado. El terrorismo dejó de ser patrimonio de la derecha al final de los 60. Che Guevara murió en 1967, una lástima. Aunque estimuló de manera insensata a la guerrilla en América Latina y en el mundo, quizás hubiera sido capaz de impedir el giro terrorista en nuestro continente. Era el único que tenía la autoridad moral para hacerlo.

La historia del terrorismo demuestra que él no está sujeto a una ideología. La acción violenta destinada a matar y a producir terror con fines políticos es una práctica que abarca todo el

\footnotetext{
${ }^{5}$ Che Guevara, La Guerra de Guerrillas, ver en: http://www.angelfire.com/de2/cheguevara/arquivos.htm (leído en 01/06/2012)

${ }^{6}$ En situaciones insurreccionales los clásicos marxistas aceptaban un poco más al terror, ver: Léon Trotsky, Terrorismo y Comunismo. Ediciones Politica Obrera. Buenos Aires, 1965.

${ }^{7}$ Carlos Marighella, Manual do Guerrilheiro Urbano, ver en:http://www.angelfire.com/ de2/cheguevara/arquivos.htm (leído en 01/06/2012).
} 
espectro de izquierda y de derecha por igual, a pesar de que su nombre no siempre sea reclamado de forma explícita, tal como lo hizo el líder brasileño. Durante el siglo 19 y las primeras décadas del 20 el terrorismo estuvo involucrado principalmente a la izquierda anarquista y al nacionalismo separatista. Sin embargo, entre las dos guerras mundiales, los principales responsables por actos terroristas fueron de la extrema derecha fascista. En el contexto de la Guerra Fría el terrorismo surgió asociado a movimientos de extrema izquierda revolucionaria o de tipo nacionalista y/o separatista, abarcando tanto a países desarrollados de Europa, como a subdesarrollados de América Latina, África y Asia. Por último, en el final del siglo 20 y principio del 21, surgió el terrorismo basado en la religión, como el de la organización islámica Al-Qaeda, que atacó las torres del WorldTrade Center. Este último fue acompañado por la Guerra contra el Terror del gobierno Bush, que utilizó el concepto como una etiqueta para identificar a la mayoría de los enemigos de los Estados Unidos, complicando aún más la comprensión del fenómeno.

Con el terrorismo de Estado pasa lo mismo, cualquier ideología o mentalidad, ya sea de izquierda, de derecha, nacionalista o religiosa, puede acompañarlo. A pesar de sus diferencias, la Alemania de Hitler, la Rusia de Stalin, la China de Mao, la Argentina de Videla, la Serbia de Milosevic, la Camboya de Pol Pot, y el Irán de Ahmadinejad, entre otros, son Estados igualmente responsables por actos de terrorismo. Los comentarios anteriores permiten concluir que el fenómeno del terrorismo no debería ser caracterizado por sus objetivos, extremamente variados, sino por su capacidad para "envenenar" los conflictos llevando la violencia (y la confusión conceptual) hasta los extremos.

En América Latina, no todas las guerrillas urbanas fueron igualmente terroristas. Los Montoneros de Argentina fueron probablemente el grupo que más adoptó este modelo de acción en los años 70, mientras que los Tupamaros de Uruguay, los que menos. Por lo tanto, también será distinta la responsabilidad histó- 
rica de cada grupo por la instalación de la dialéctica de violencia de cada país.

En esa época nadie pensaba que una organización revolucionaria, aun cuando pusiera bombas y matara personas inocentes, pudiera ser terrorista. Igual que mis compañeros, yo era un terrorista de alma bella. La verdad es difícil de aceptar no sólo para aquellos que fueron guerrilleros, sino para la mayoría de los argentinos. Algunos autores sostienen que durante la dictadura militar, desde Onganía hasta Lanusse, el actor principal de la lucha revolucionaria fue la guerrilla y no el terrorismo, el cual aparecería progresivamente a partir de 1974, con el gobierno constitucional de Isabel Perón. Esta interpretación intenta dividir la lucha armada en dos fases, pero ocurre que en el caso de Montoneros la lógica e intencionalidades del terrorismo estuvieron presentes desde su primera acción pública: el secuestro y ejecución del general Aramburu, en 1970. Este debate es fundamental para la comprensión de las responsabilidades en el proceso de violencia que causó diez mil muertes trágicas cuya autoría, en una cuenta aproximada, fue de mil (1000) por la Triple $A,{ }^{8}$ mil (1000) por las organizaciones revolucionarias y ocho mil (8000) por las fuerzas militares de la dictadura de Videla. Esta es una cuenta que, en la defensa de la dignidad de la historia argentina, se tendría que haber hecho con precisión y consenso público hace mucho tiempo. Mostrando falta de coherencia y bies ideológico, esta cuenta no está en la lista de las reivindicaciones de los movimientos o de los organismos estatales que se ocupan de los derechos humanos en la Argentina.

En la Argentina hubo guerrilla y terrorismo superpuestos casi desde el comienzo de la violencia revolucionaria. El terrorismo

\footnotetext{
${ }^{8}$ La Alianza Anticomunista Argentina, conocida como Triple A, fue un "escuadrón de la muerte” creado durante el gobierno de Perón e Isabel Perón (1974-1976) con el objetivo de asesinar a los militantes y simpatizantes de las organizaciones guerrilleras. Fue integrada por civiles y miembros de las fuerzas de seguridad (retirados y en actividad).
} 
se presentó con un rostro bien definido en la ejecución del sindicalista peronista Vandor en 1969 (figura principal de la Confederación General del Trabajo - CGT, colaboracionista con la dictadura de Onganía y adversario de Perón), del general Aramburu en 1970 (arquitecto de la Revolución Libertadora que derrocó a Perón y presidente del gobierno de facto de 1955 a 1958), del sindicalista peronista Rucci en 1973 (secretario general de la CGT y aliado muy próximo de Perón), y del ex-ministro Mor Roig en 1974 (político ajeno al peronismo que como ministro del gobierno del general Lanusse articuló el pacto que permitió el retorno de la democracia en 1973). Todas las operaciones fueron realizadas por comandos Montoneros (o que se integrarían después en la organización, como en el caso de Vandor). Los dos últimos asesinatos fueron perpetrados a pesar del país estar bajo un régimen democrático, varios años antes de la llegada de la dictadura militar.

Entre otras cosas, el uso del terrorismo fue facilitado entre los Montoneros por la amalgama de componentes ideológicos contradictorios que impedían pensar en estrategias políticas realistas y coherentes. Al mismo tiempo, estos grandes gestos terroristas eran funcionales para el crecimiento de la organización, permitiendo sumar militantes de diversas corrientes ideológicas. Ellos podrían venir tanto del catolicismo nacionalista de derecha, como de la teología de la liberación marxista, del peronismo revolucionario de derecha como del comunismo, y otras variantes de la izquierda. Los Montoneros surgieron y consolidaron su organización en el culto a la violencia. Ellos fueron capaces de matar a todos los que se cruzaron por delante de su voluntad política, sin importarles su condición, ya sean peronistas o antiperonistas, militares, políticos o sindicalistas.

Sin embargo, soy testigo de que nuestra motivación era noble. Conservo todavía un recuerdo feliz de mi vida en aquellos años. Fueron sombríos pero también llenos de desprendimiento, alegría y amor. Yo sé que nuestra intención no era hacer el mal por 
el mal en sí mismo, pero la "astucia de la razón”, irónica y perversa, pudo convertir hombres buenos en malos, sin darnos tiempo para tomar conciencia. ${ }^{9}$ El retorno de este camino sería extremamente difícil para la mayoría, casi imposible.

Los Montoneros ocultaron su ambición de poder por detrás del liderazgo de Perón, pero cuando se dio su retorno, y él no les entregó la dirección del movimiento peronista como esperaban, no dudaron en matar a Rucci para llamar la atención del líder sobre sus demandas, pero sin reconocer públicamente su autoría. Creían que la condición de revolucionarios les otorgaba el patrimonio de la historia, por ser dueños de la verdad se permitieron mentirles a sus contemporáneos (en el otro extremo del espectro político argentino la situación seria semejante, la historia mundial está llena de ejemplos de este tipo). Del mismo modo, años antes habían matado al general Aramburu para ser reconocidos como peronistas por Perón y por las masas. Así como intentaron ocultar la verdad de la muerte de Rucci, en el caso de Aramburu intentaron hacer desaparecer su cuerpo, con la supuesta intención de cambiarlo en el futuro por el de Eva Perón, secuestrado durante el gobierno de Aramburu.

Como Eva Perón murió de muerte natural, la saga de las desapariciones de personas asesinadas con intencionalidad política en la Argentina del siglo 20 no la incluye. Según mi conocimiento, esta triste saga comenzó en 1930 con el anarquista Penina, durante el gobierno del general Uriburu; siguió en 1955, con el comunista Ingalinella, en el gobierno del General Perón; continuó en 1962 con el peronista Vallese durante el gobierno provisional de Guido (que asumió tras el derrocamiento de Frondizi por los militares); hasta llegar al cuarto de la lista, el general Arambu-

\footnotetext{
${ }^{9}$ El concepto de "astucia de la razón" fue usado por Georg W. F. Hegel para poner en evidencia el desacuerdo entre los hombres, que creen estar haciendo su propia historia, y la realidad, conducida por una dinámica que castiga sus pretensiones al producir resultados contrarios a las expectativas.
} 
ru, cuyo cadáver permanecería desaparecido un mes y medio. El imaginario de los autores de la larga lista desaparecidos que vendría después se construyó con base en estos antecedentes.

Debido a que el asesinato de Rucci provocó una acelerada ascensión a los extremos de violencia, envenenando el gobierno de Perón en plena democracia, este atentado debería considerarse como el mayor acto terrorista de la guerrilla argentina en los años 70. Sin embargo, por ser un magnicidio, otro que convocó igualmente a los demonios fue el de Aramburu. Su cuerpo demoró para descansar en paz. Además del desaparecimiento sufrido después de su muerte, cuatro años después de enterrado en el Cementerio de la Recoleta volvería a pasar por lo mismo. Los Montoneros repitieron la hazaña para continuar insistiendo en la devolución del cadáver de Eva Perón. La trágica ironía de este último hecho es que el cuerpo de Evita había sido entregado a Perón en España tres años antes, en 1971: ¡era el general vivo que no lo quería traer de vuelta al país, no el general muerto! Si la primera desaparición del cadáver de Aramburu podía reivindicar alguna legitimidad, la segunda no tenía ninguna razón más que insultar la memoria de los militares argentinos. En favor de los Montoneros se podría decir que la falta de respeto a los muertos tiene una larga historia en la Argentina; el cadáver de Perón tampoco se salvó y tuvo sus manos mutiladas en 1987.

El escenario terrorista argentino de los años 70 tuvo todas las combinaciones posibles de terrorismo, uno más vinculado a los movimientos de la sociedad civil, otro más a los organismos estatales, y también casos intermedios, como la Triple A. Todos se retroalimentaron entre sí. Obviamente, no todos los miembros del Estado o de la sociedad civil fueron terroristas de la misma forma a lo largo de la historia. Sin embargo, hubo complicidad en diversos niveles del Estado y la sociedad civil con el terrorismo producido por los gobiernos de Lanusse, Perón, Isabel Perón, Videla, Viola y Galtieri. Así como hubo complicidad con el terrorismo de las organizaciones guerrilleras en distintos niveles de 
la sociedad civil y del Estado (especialmente en el gobierno de Cámpora y de algunos gobernadores provinciales en 1973).

Es falso afirmar la existencia de un "terrorismo de Estado", como si fuera una entidad pura y separada del resto de la sociedad, tal como pretenden las organizaciones de derechos humanos y el gobierno de los Kirchner. Un terrorismo no es más o menos terrorista en función de su origen, sino de su contribución a la dinámica de terror dentro de una comunidad política. Si un movimiento terrorista, venga de donde venga, pretende exterminar un grupo aislado e indefenso, ya sea nacional, étnico, racial, religioso, cultural o identitario - como, por ejemplo, armenios, bosnios, tutsis, gitanos, homosexuales, indígenas, judíos, musulmanes, cristianos, etc. - eso constituye el peor terrorismo imaginable, lo que el derecho internacional llama un crimen contra la humanidad. Sin embargo, el terrorismo ejercido en un contexto de guerra o de conflicto por el poder entre grupos armados (de manera regular o irregular), no constituye un crimen contra la "humanidad" - a pesar de lo que digan los juristas - sino contra el colectivo en el que se insertan los beligerantes. En el caso argentino, tanto el terrorismo que venía del Estado como el que se practicaba desde la sociedad civil eran ejercidos en contra de la comunidad política argentina. Por lo tanto, a pesar de que los crímenes individuales puedan ser diferenciados por sentencias y puniciones legales mayores o menores, el terrorismo de los Montoneros, la Triple A y la dictadura militar son igualmente graves, ya que contribuyeron solidariamente a una ascensión a los extremos de la violencia.

La "humanidad", como categoría empírica (social, religiosa o política) no existe. Un europeo y un indio de la Amazonia tienen, en cualquier nivel, más diferencias que similitudes. La humanidad es sólo una convención moral que, en todo caso, podría identifi- 
car a aquellos grupos pasivos e impotentes frente a la violencia, pero nunca a los que participan activamente en los conflictos armados, como pasó en el caso argentino, donde hubo, sí, víctimas inocentes y ajenas al conflicto, pero que no fueron el objetivo principal del terror, ni de un lado ni del otro. Los museos "de la memoria" construidos durante el gobierno de los Kirchner registran solamente a las víctimas de un lado, pero no del otro, ocultando el hecho de la beligerancia compartida. Y para intentar una mejor construcción del supuesto crimen contra la humanidad de los militares, sus víctimas son transformadas en inocentes sin ningún tipo de identificación o vínculo con las organizaciones guerrilleras. En algunos casos este vínculo pudo no existir, pero cuando existe, en nombre de los derechos humanos el gobierno está suprimiendo la identidad revolucionaria de los "compañeros". No le hace justicia a la historia, ni al compañero o la compañera, que se recuerde como estudiante o empleado a quien, por ejemplo, enfrentó a la muerte con el grado de oficial de los Montoneros.

En resumen, la víctima es una persona, pero el terrorismo se ejerció a través de ella en contra de su comunidad política. Aunque en menor grado, todos aquellos que colaboraron de una u otra manera se convirtieron en sus cómplices y, por lo tanto, también deberían ser procesados legalmente. Me pregunto entonces, ¿cuántos deberían estar en el banquillo de los acusados por la lucha armada estallada en los años 70 en Argentina? Ciertamente, muchos más de los que están. Los argentinos que fueron testigos de aquella época saben que una proporción significativa de la población, especialmente losjóvenes de la generación de los años 60, apoyaban a la guerrilla, así como otra parte no menos significativa, sobre todo de la generación anterior de los años 40 , hacía lo mismo con los militares. Preguntémonos también cuál es el peor terrorismo desde el punto de vista conceptual e histórico. ¿Es peor aquel realizado en nombre del asalto al poder o en nombre de la defensa del Estado? No hay ninguna legitimidad en el terrorismo al servicio del asalto al poder en un con- 
texto democrático, como ocurrió en el período de 1973 a 1976, durante el cual las organizaciones guerrilleras continuaron comportándose casi de la misma manera que antes con la dictadura. Para la guerrilla no peronista nada había cambiado con la llegada de la democracia. Aunque la guerrilla peronista declaró una suspensión de sus operaciones armadas, en el caso de los Montoneros la tregua fue más aparente que real. Formalmente, la tregua concluiría en septiembre de 1974, pero las ejecuciones y las grandes acciones de los Montoneros empezaron de manera deliberada un año antes.

El terrorismo no tiene ninguna legitimidad - aun luchando contra una dictadura - si lo que quieren sus ejecutores es hacer una revolución para imponer nuevas reglas de juego. En este caso, como bien declaró Thomas Hobbes, el fundador de la teoría política moderna, en su libro Leviatán (1651), la legitimidad se logra solamente cuando el grupo revolucionario o subversivo toma el poder, nunca antes. Esto no es reaccionarismo, sino una obviedad histórica y constitucional: el cambio de las reglas del juego, especialmente en un sentido revolucionario, no tiene a priori legitimidad o legalidad, en ningún tipo de régimen político o ideología política. Esto vale tanto para el Estado liberal, como para el socialista, ya sean democráticos o autoritarios. La principal obligación del Estado es defender su existencia con los medios a su alcance. Como afirma Hegel en su Filosofía del Derecho (1821), el Estado, aunque imperfecto en su realización particular, sigue siendo la institución superior de la historia humana civilizada. El terrorismo contra el Estado es extremadamente peligroso porque fomenta fuerzas anti-estatales en su seno que lo degradan rápidamente en la dirección de la barbarie. Paradójicamente, la única alternativa que resta a los grupos subversivos y terroristas de izquierda para ganar legitimidad, antes de la toma del poder, viene de la mano del liberalismo que ellos tanto desprecian. John Locke, fundador reconocido de esa corriente y cuyas ideas fundamentan las concepciones de derechos humanos y democracia moderna desde el siglo 17, justifica 
claramente la revuelta de los ciudadanos contra el abuso de poder de los gobernantes. En el Segundo Tratado sobre el Gobierno Civil (1690), Locke afirma que los hombres tienen derechos naturales antes de la existencia del Estado, lo que hace posible la rebelión cuando ellos le son negados, a fin de recuperarlos. Dicho de otro modo: la revolución solamente es legítima para restaurar los derechos perdidos, no para imponer nuevos derechos u obligaciones.

Volviendo al caso argentino, la legitimidad de la lucha armada se agotó el 25 de mayo de 1973, en el momento en el que todos los presos políticos fueron liberados, después de que el general Lanusse le hubiera entregado el mando presidencial a Cámpora, un presidente civil elegido en elecciones limpias, aceptadas por todos los partidos después de casi veinte años de proscripciones. A partir de ahí la ilegitimidad de los grupos guerrilleros fue total. Fueron ellos los primeros a llevar el terror a la nueva democracia, un terror que fue respondido enseguida y de la misma forma por la Triple A, apoyada por el gobierno. Estos terrores generaron el estado de anarquía que justificaría el golpe militar de 1976, una intervención que fue deseada por los Montoneros y otras organizaciones, imaginando que la salida del gobierno constitucional traería al campo revolucionario un mayor número de fuerzas. La dictadura militar instalada en 1976 decidió avanzar con ímpetu asesino contra aquellos que habían asumido la lucha revolucionaria, pero la legitimidad acumulada por la guerrilla en la lucha contra la dictadura militar anterior, había desaparecido por completo debido a su lucha contra el régimen democrático constituido en 1973. Por lo tanto, la lucha guerrillera contra la nueva dictadura militar no fue solamente suicida, sino también ilegítima. Y a pesar de haber sido demoníaca e ilegal, a pesar de haber llegado a extremos a los cuales la guerrilla nunca llegaría, la lucha de la dictadura contra la subversión fue legítima. Este juicio no es una mera opinión: por detrás está la tradición política y democrática occidental. La Argentina de esos años no tuvo combatientes, ni héroes. La lucha convirtió a to- 
dos en víctimas y victimarios recíprocos. Hubo más víctimas en un lado que en otro, pocos inocentes y muchos culpables. Sin embargo, hubo sentencias solamente para los militares y sus aliados.

\section{Referencias Bibliográficas}

ARENDT, Hannah. Sobre a Revolução. Lisboa: Relógio D’Água, 2001.

VON CLAUSEWITZ, Carl. Da Guerra. São Paulo: Martins Fontes, 2010.

CHE GUEVARA, Ernesto. La Guerra de Guerrillas. En: http://www.angelfire. com/de2/cheguevara/arquivos.htm (leído en 01/06/2012).

MARIGHELIA, Carlos. Manual do Guerrilheiro Urbano. En: http://www.angelfire.com/de2/cheguevara/arquivos.htm (leído en 01/06/2012).

Recebido em 10.08.2013

Aprovado em 20.10.2013 